Arxiu d'Etnografia de Catalunya, $\mathrm{n}^{\circ}$ 6, 1988, 60-86

ISSN: 0212-0372. EISSN: 2014-3885

http://antropologia.urv.cat/revistarxiu

ARXIU D'ETNOGRAFIA DE CATALUNYA. N. 6. 1988

\title{
CICLE FAMILIAR I TRANSMISSIO DE LA PROPIETAT AL PRIORAT: ELS FABREGAT
}

\author{
Xavier ROIGE i VENTURA \\ Universitat de Barcelona \\ Institut Català d'Antropologia
}


Aquest article vol ser una aproximació a alguns aspectes de l'estructura familiar del camperolat i la importància dels mecanismes dherencia i estratègies matrimonials per a la formació i manteniment de lestructura de propietat i de classes. a partir de l'estudi concret duna familia camperola durant un segle i mig. Hom pretén mostrar que el que sovint es presenta com a un conjunt de normes atemporals que regeixen les practiques de parentiu. són sobre tot un sistema normatiu ideal. susceptible d'adaptar-se en cada moment históric a les condicions economiques. socials i demográfiques particulars. En el cas estudiat. les normes d'herència $\mathrm{i}$ residència interactuen en cada circumstancia socio-histórica per portar-se a la pràctica de formes molt diverses en funció de les condicions familiars especifiques (nombre de membres. relacions de parentiu establertes. morts, etc.) i condicions socials globals (conjuntura economica. possibilitats de comercialització de la collita. oferta i demanda de força de treball. etc.).

Malgrat les representacions restringides $\mathrm{i}$ aillades que es fan de les normes de parentiu a les societats camperoles. nosaltres creiem que cal englobar-les en relació als altres nivells de la realitat social. com a fenomen politic i economic integrat en la totalitat social.

Per aixó. deixant de banda anàlisis idealistes $\mathrm{i}$ uniformistes. veuriem en la transmissió patrimonial un grau elevat dadaptabilitat i d oportunitat. En la nostra perspectiva. la familia estudiada tindrả en compte en cada moment del seu cicle domèstic les millors possibilitats i oportunitats per al manteniment i increment del seu patrimoni. raó per la qual moltes vegades deixará de portar-se a la pràctica el comportament normatiu ideal. En aquest sentit. lanàlisi dels afers patrimonials presenta un comportament distintiu de classe. de manera que dificilment podrem generalitzar els comportaments i actituds en relació a la transmissió patrimonial. En el nostre cas. la funció del parentiu serà essencialment socio-politica: la familia estudiada tractarà d'adequar sempre les estrategies i sol-lucions d'herència més favorables per al manteniment de la seva posició economica i. en conjunt. les families benestants desenvoluparan els mecanismes que en cada moment creguin més adequats per a impedir laccés a la propietat dels altres grups socials i també per a dotar-se de la impermeabilitat que com a grup necessita. La dinàmica del cicle doméstic esdevé aixi més complexa que una simple i mecànica transmissió patrimonial segons les normes d'herència. Com assenvala Fauve-Chamoux. cal que l'historiador demograf es faci sociòleg uper comprendre les aliances. apreciar les solucions de recanvi. descobrir les formes de solidaritat familiar. ensumar els conflictes $i$ el refús que produeixen els nombrosos solitaris. dones soles i noves cases" (Fauvè-Chamoux. 1984:527). 


\section{Context Socio-Històric}

Els Fabregat eren una familia de propietat mitjana de Gratallops, al Priorat. Com es coneix. aquesta és una comarca on predomina el monoconreu de la vinva: a Gratallops. les vinyes ocupaven. l'any 1900 el $89.7 \%$ de la superficie cultivada. i el 1963 era encara del $71 \% .^{2}$ Aquest fet ha determinat que l'organització de la propietat i les condicions de producció $5^{*}$ articulin amb l'estructura i conjuntura del mercat al llarg del periode analitzat. L'explotació de la vinya es fa en muntanyes de marcats declivis. pedregosos. sense valls. en unes condicions que generen una rendabilitat molt baixa de les explotacions. caracteritzades en l'actualitat per una manca de mecanització i que. en definitiva. es necessiti d'una força de treball abundosa. especialment en els moments de la verema.

Leepoca que analitzarem. segles XIX i primera meitat del XX. comportả una sèrie de transformacions econòmiques $\mathrm{i}$ socials bàsiques que poden dividir-se en dos periodes. separats per la frontera de la crisi vinicola i comercial de la fil.loxera. El primer. amb anterioritat a aquesta crisi (detectada cap al 1893). es caracteritza per un creixement constant de la superficie cultivada. gràcies a les bones possibilitats de comercialització, $\mathrm{i}$ a lintent d'implantació d'una producció de tipus liberal, amb l'ascens d'una classe de propietaris locals que anirien adquirint bona part de la propietat mitjançant estratègies matrimonials, control de la producció i del poder politic local. En aquest context. el que determina les diferències de classe no és tant l'accés a la propietat com el volum d'aquesta propietat. La majoria de la població tenia una explotació consistent en tres elements (una casa familiar. una parcel-la de vinya o tros, i una petita parcel.la de regadiu per al consum familiar. o hortet). però les diferències venien marcades per la superficie de les explotacions de vinya, cosa que obligava als petits propietaris a treballar com a jornalers o parcers de les famílies benestants. D'aquesta manera. es generarien tres classes socials diferenciades $i$ oposades: les families benestants. amb explotacions de més de 20/30 $\mathrm{Ha}$. de conreu: els mitjans. amb una superficie suficient per cobrir les seves necessitats però que. aixi i tot. treballaran esporàdicament com a jornalers: $\mathrm{i}$ els petits propietaris. amb una explotació pròpia sempre inferior a les $2 \mathrm{Ha}$.. que generarà uns recursos totalment insuficients per el propi manteniment. que només podran assegurar mitjançant el treball a les terres dels benestants (Roigé. 1984). Aquests, a més s'asseguraven també el control de la producció de la majoria de productors, pel fet de disposar dels elements necessaris per a fer el vi. que no tothom tenia (cups. cellers. animals de transport. etc.) i per les seves relacions directes amb els majoristes que compraven el vi. Finalment. formant una classe hegemònica i compacta. participarien activament en activitats politiques, controlant el poder local mitjançant relacions de clientela. corrupció municipal i practica activa del caciquisme.

El factor determinant de l'expansió vinicola del XIX foren les bones possibilitats de venda als mercats colonials dÁmèrica i França. Però l'expansió va fer-se sense una inversió capitalista suficient, a costa d'unes condicions de sobre-treball dels rabassaires $i$ jornalers. d'uns jornals molt baixos propiciats per uns excedents demogràfics i del guany de molta 
superficie (en terrenys poc adequats per al conreu). sense incrementar en absolut les condicions de productivitat. Larribada de la fil-loxera. simultàniament amb el tancament dels mercats colonials i dels francesos. determinà que el Priorat passés de ser una comarca privilegiada per a les inquietuds de la burgesia. a ser una comarca marginal. amb una estructura de producció inadequada per a les noves necessitats del mercat. Encara el 1910. la producció de vi era un $76 \%$ més baixa a lanterior de la fill-loxera. mentre la població passà de 903 habitants. el 1887. a 662. el 1910. Aquests canvis es deixaren sentir en lestructura de la propietat i. sobre tot. en els conflictes entre classes. Els grans propietaris. malgrat llur major possibilitat de recuperació. adoptarien sobre tot una actitud de defensa de la seva posició privilegiada. servint-se sobre tot del control politic per al manteniment del seu status sense procurar invertir excessivament en la millora de les condicions de productivitat. ${ }^{-}$A la vegada. els propietaris més petits anirien emigrant. mentre els salaris dels jornalers sincrementarien considerablement. En aquestes circumstancies, si bé les grans propietats s'han mantingut. els mitjans han anat consolidant-se i han deixat de ser una classe dependent. en el sentit que. avui. el treball com a jornalers o parcers és. pràcticament inexistent.

Peró fixem-nos més en l'estructura de la propietat. parentiu i herència. En lảmbit de la Catalunya Nova. el grup domestic presenta segurament una menor extensió i la institucionalització de la transmissió patrimonial indivisa (hereu primogènit) és menys rigida que a la Catalunya Vella. encara que els mecanismes d'herència són molt diferents. segons la classe social que els adopti.

Amb caràcter de sondeig. hem realitzat una reconstrucció dels grups de residència. segons la classificació de P. Laslett. per als anys 1792 i 1975 (quadre núm. 1). En funció d’aquestes dades. les unitats domèstiques de tipus nuclear constituien el $66.3 \%$ el 1792 i el $59.1 \%$ el 1975 . mentre que les de carảcter extens i múltiple sumaven el $28.4 \%$ i el $21.6 \%$. respectivament. Entre ambdues dates, peró. el canvi mes notable es percep en el gran increment dels "solitaris", que del $5.1 \%$ passen al $19.3 \%$. Comparant aquestes dades amb les obtingudes en els nombrosos estudis inspirats per la classificació de Laslett (1972). que donen per al Nord d'Europa un predomini de families nuclears amb proporcions superiors al $70 / 75 \%$. la taxa d'unitats residencials nuclears és aqui més baixa. situant-se a l'entorn del $60 / 65 \%$. d'acord amb d'altres anàlisis de l'Europa meridional: FauvéChamoux troba en el Pirineu, un «regne de les families troncals». una proporció del 58.2\% de families nuclears (Fauvé-Chamoux. 1984:517). El domini de l'estructura nuclear segueix essent. peró. clar.

Tanmateix. aquestes dades poden representar diversos problemes d'interpretació. per dues raons essencials. En primer lloc. perquè reprodueixen un moment estàtic del desenvolupament familiar. ignorant el moviment sequencial. de manera que les families nuclears poden ser fases diun desenvolupament de famílies més àmplies (a causa de morts. casaments. etc.). podent ser. doncs. estadis de fisió i fusió del desenvolupament de families extenses. En una societat de casament a edats elevades (sempre superior als 25 anys, per als homes i 24 anys per a les dones. com a mitjana del s. XIX), i d'una alta mortalitat. fa que la possibilitat d'aplegat 
Arxiu d'Etnografia de Catalunya, $\mathrm{n}^{\circ} 6,1988,60-86$

ISSN: 0212-0372. EISSN: 2014-3885

http://antropologia.urv.cat/revistarxiu

Quadre 1.- Esmuchura de les unitats doméstigues a Gratallops ${ }^{6}$

\begin{tabular}{|c|c|c|c|c|}
\hline & 1792 & & 1975 & \\
\hline Tipologia & nombre & $\%$ & nombre & $\%$ \\
\hline 1. SOLIT ARIS & 10 & 5.1 & 18 & 19.3 \\
\hline $\begin{array}{l}\text { 1) Didus } \\
\text { h. Solters }\end{array}$ & $\begin{array}{l}7 \\
3\end{array}$ & $\begin{array}{l}3.5 \\
1.6\end{array}$ & $\begin{array}{r}11 \\
7\end{array}$ & $\begin{array}{r}11.8 \\
7.5\end{array}$ \\
\hline 2. F. SE NSE NUCLI CONJUGAL & 0 & 0.0 & 1 & 1.1 \\
\hline \multicolumn{5}{|l|}{ a) Germans nes } \\
\hline $\begin{array}{l}\text { 3. F. AIB NLCLI CONJUGAL } \\
\text { SIMPLE }\end{array}$ & 130 & 66.2 & 54 & 58.0 \\
\hline $\begin{array}{l}\text { a) Parella sense fills } \\
\text { b) Parella amb fills } \\
\text { c) Vidu amb fills } \\
\text { d) Vidua amb fills }\end{array}$ & $\begin{array}{r}22 \\
93 \\
5 \\
10\end{array}$ & $\begin{array}{r}11.2 \\
47.4 \\
2.5 \\
5.1\end{array}$ & $\begin{array}{r}21 \\
30 \\
2 \\
1\end{array}$ & $\begin{array}{r}23.0 \\
31.7 \\
2.2 \\
1.1\end{array}$ \\
\hline 4. F. EXTEXSES & 31 & 15.7 & 10 & 10.8 \\
\hline $\begin{array}{l}\text { a) Extensa als ascendents } \\
\text { b) Extensa als descendents } \\
\text { c) Extensa als colaterals }\end{array}$ & $\begin{array}{r}24 \\
3 \\
4\end{array}$ & $\begin{array}{r}12.2 \\
1.5 \\
2.0\end{array}$ & $\begin{array}{l}7 \\
2 \\
1\end{array}$ & $\begin{array}{l}7.5 \\
2.2 \\
1.1\end{array}$ \\
\hline $\begin{array}{l}\text { 5. F, AMB NUCLIS CONJUGALS } \\
\text { MLLTIPLES }\end{array}$ & 19 & 9.7 & 8 & 8.6 \\
\hline $\begin{array}{l}\text { a. b) tmb nucli conjugal } \\
\text { ascendent o descendent }\end{array}$ & 19 & 9.7 & 8 & 8.6 \\
\hline 6. ALTRES & 6 & 3.0 & 2 & 2.2 \\
\hline $\begin{array}{l}5 b+4 a \\
5 b+4 b \\
3 c+4 b\end{array}$ & $\begin{array}{l}5 \\
1 \\
0\end{array}$ & $\begin{array}{l}2.5 \\
0.5 \\
0.0\end{array}$ & $\begin{array}{l}1 \\
0 \\
1\end{array}$ & $\begin{array}{l}1.1 \\
0.0 \\
1.1\end{array}$ \\
\hline $\begin{array}{l}\text { TOTAL EXTENSES I MÚLTIPLES } \\
(4+5+6)\end{array}$ & 75 & 28.7 & 20 & 21.6 \\
\hline TOTAL & 196 & 100 & 93 & 100 \\
\hline Mitjana persones grup residència & 5,2 & & 3.3 & \\
\hline
\end{tabular}


diverses generacions completes resulti dificil. encara que la tendencia sigui aquesta. En aquest sentit. un cens «casa per casa» es com un àlbum de fotografies en què els clitxés s'han pres simultàniament (Collomp. 1974:781). peró ens cal una sèrie fotográfica duna mateixa familia per a copsar que la seva estructura pot ser nuclear. múltiple o extensa. segons la fotografia que es miri. transformant-se succesivament duna a laltra.

Caldrà recórrer a la reconstrucció del cicle domestic (com l'exemple que proposem). per a determinar quines sỏn les pautes de residència predominants. veient les diverses fases de contracció i expansió duna familia. En el cas que analitzem. a més dels censos de població. hem utilitzat d'altres fonts que permeten seguir l'evolució dinàmica del cicle familiar: actes parroquials i civils. documents juridics $\mathrm{i}$ capitols matrimonials. cadastres. etc. Aquesta diversificacio documental fa possible relacionar els components familiars no només per les seves formes de residència. sinó també per continguts econòmics. geogràfics. socials i politics. El cicle estudiat permet aixi donar una dimensió nova i dinàmica a les classificacions estàtiques impulsades pels estudis de Laslett.

En segon lloc, i per nosaltres tant o més important. Laslett i els seus collaboradors obliden la diversitat que planteja l"ocupació de posicions economiques diferents. Com assenyala Stone (1977:23). les families més riques són més complexes. La familia extensa és considerada com la situació ideal, i és molt més frequent entre les families benestants. Aquest ideal. només podia realitzar-se si ei volum de la propietat era suficient com per a mantenir un ampli nombre de persones. Ans al contrari. en tant que els ingressos dels petits propietaris $i$ dels jornalers es fonamenten en uns recursos que no depenen de llurs propietats. els caldrà limitar el nombre de membres adequant-lo a la força de treball disponible dins de la unitat familiar. En definitiva, no és possible reduir a uns mateixos tipus familiars estructures que pertanyen a classes diferents de manera que uns mateixos mecanismes familiars poden actuar de forma diferenciada per a una $\mathrm{i}$ altra classe (Donzelat. 1979).

Una diferència semblant s'observa quan ens referim a les normes d'herència. En aquest sentit. per al periode estudiat. existeix una dualitat

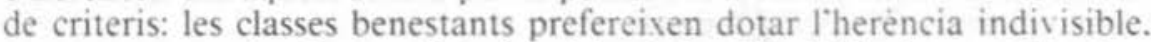
mentre que. entre els propietaris mitjants i petits. lideal normatiu consisteix en repartir les propietats entre els fills. Tanmateix. ambdós ideals semblen correspondre's poc amb la realitat. El problema fonamental es presenta en analitzar les families benestants. perque entre les altres classes no es transmet tant la propietat com la força de treball. Analitzant els criteris de transmissió patrimonial entre les families benestants resulta que aquestes tendeixen a crear. en cada circumstancia especifica. les estratègies més adequades de cara a possibilitar que els diversos fills no vegin reduïda la seva posició económica i a evitar que les altres classes puguin accedir a les seves propietats. En el sistema d'herència de la Catalunya Vella. la transmissió indivisa a una sola persona (hereu), pot dur-se a terme gràcies a l'expulsió dels fills que no rebran l'herència (vers altres professions o vers altres masies). A la zona estudiada. en canvi, hi ha tres factors que condicionen unes necessitats de transmissió patrimonial diferents: el poblament agrupat. la situació dispersa de poblament de les 
parcel-les en el terme municipal i l'estructura de classes. Els tres factors tenen una relació en comú. Convivint junts. les possibilitats d'establir un matrimoni fora de la classe a la qual es pertany és hipotèticament més alta. per la qual cosa cal establir unes limitacions més rigides. Els matrimonis amb classes inferiors serien perillosos per les families benestants perque implicarien relacionar-se amb families de posició diferent. a la vegada depenents d'altres en un sistema d'oposició de classes. Aixi. l'única estratègia possible consisteix en possibilitar que cap dels membres de la própia familia vegi rebaixada la seva condició económica. és a dir. en dotar els fills d'una propietat suficient. El fet de tenir les diverses parcel.les separades dins del terme facilita aquest repartiment i una certa circulació de les terres. Peró. tanmateix. aquest criteri és portat a la pràctica de forma ben diversa en funció de cada circumstancia particular. de cada matrimoni. de cada conjuntura economica. Si per a un fill. per exemple sha aconseguit una propietat important gracies a un matrimoni amb una altra familia benestant. probablement rebrà ben poc de la seva pròpia familia. En canvi. si mitjançant el seu matrimoni ha aconseguit poques terres. caldrá dotar-lo o transmetre-li una propietat més gran.

Definit aixi. podria semblar que entre les grans families existeix una circulació de terres frequent i uns mecanismes compensatoris tendents a dividir i aplegar continuament la propietat al llarg de generacions. Tanmateix. la pràctica demostra una transmissió de la propietat de forma doble: una part de la propietat és considerada fixa i només serà transmesa a l'hereu principal, mentre que l'altra és susceptible d'ésser repartida entre els altres fills o el mateix hereu. El fill hereu (normalment el més gran. però no obligatòriament), rebrà com a minim els tres elements bàsics que constituien un patrimoni familiar. és a dir. la casa. una parcel.la de regadiu i una o més parcel.les de vinya (normalment. algunes de les parcel-les de vinya es consideren relacionades amb el patrimoni familiar. de manera que sempre seran transmeses al mateix fill que rebrà la casa). Aquest criteri es manifestará fins i tot quan. després de la crisi de la fil-loxera i especialment a partir del 1930. algunes grans families. per manca de jornalers $\mathrm{i}$ parcers suficients. es veuran obligades a dividir llurs terres entre els fills per a repartir la força de treball.

Com s'observa, aquesta concreció pràctica de lideal revela un ampli marge d'adaptació a cada circumstància especifica. a la composició real que s`assumeixi. Per aixó resulta bàsic l'anàlisi del cicle domèstic, com proposa Fortes (1958) indicant que els models de residència no són més que el resultat de processos diferencials de desenvolupament d'uns mateixos principis d'organització. L'estudi concret que segueix pretén mostrar. sobre tot. aquests aspectes. Quan se'ns presenta el que només són models ideals com a normatius, es cau en l'errada d'una perspectiva descontextualitzada $\mathrm{i}$ atemporal que només indica les relacions familiars existents a l'interior del grup, sense representar els aspectes conflictius o injustos de la transmissió familiar (Comas d’Argemir. 1984:64). La nostra anàlisi pretén mostrar, a partir d'un cas particular. les possibilitats metodológiques que ofereix una anàlisi històrica d una familia, sobre tot perquè ens permet una contextualització dels fenòmens particulars en relació als generals. podent així comprovar els efectes concrets de signe general i 
Arxiu d'Etnografia de Catalunya, $n^{\circ} 6,1988,60-86$

ISSN: 0212-0372. EISSN: 2014-3885

http://antropologia.urv.cat/revistarxiu
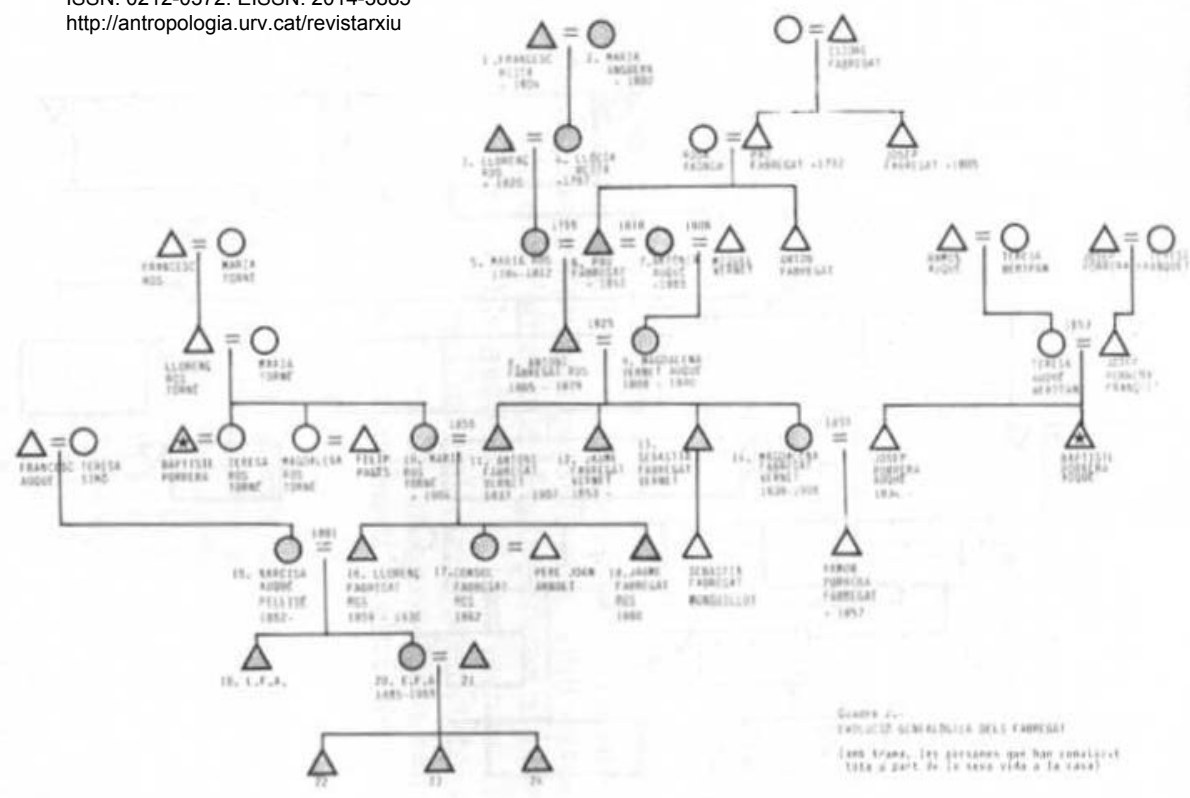
Arxiu d'Etnografia de Catalunya, $n^{\circ} 6,1988,60-86$

ISSN: 0212-0372. EISSN: 2014-3885

http://antropologia.urv.cat/revistarxiu

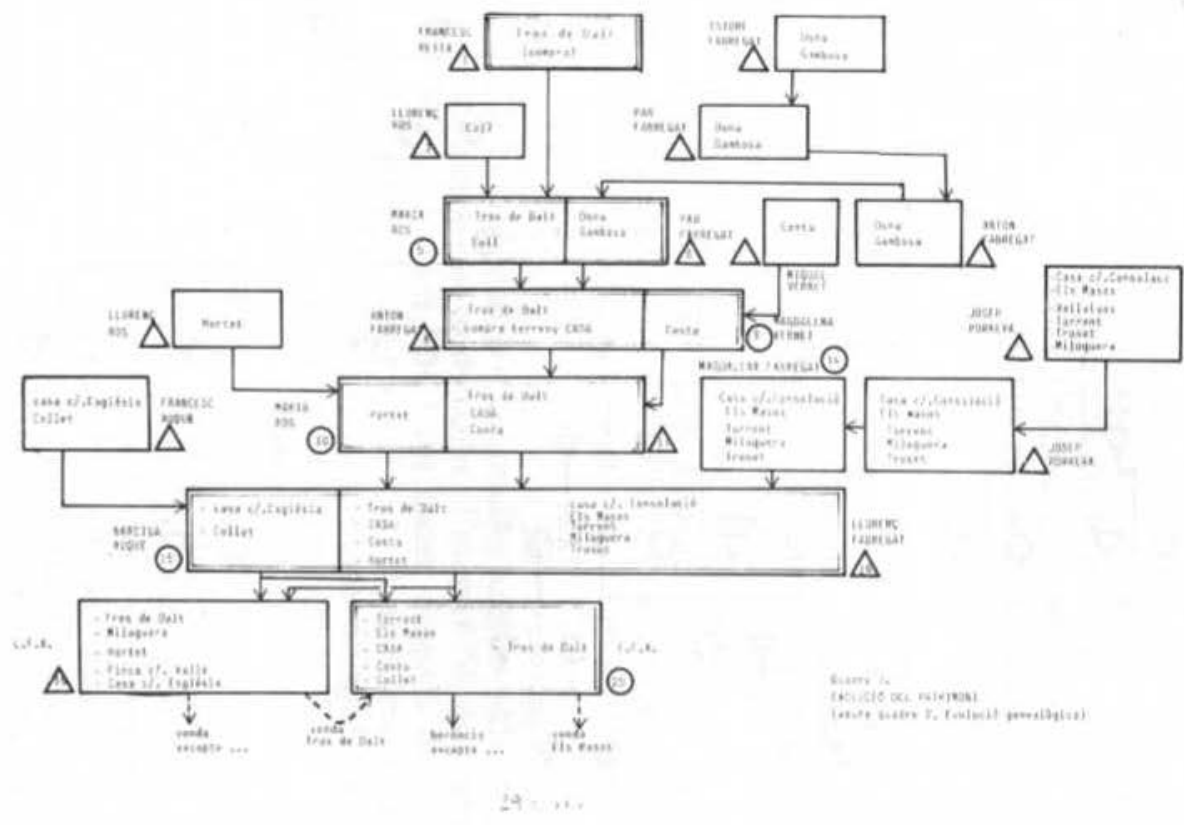


apreciar. en definitiva, quina és la interrelació dels fenòmens conjunturals genealógics (interns de la pròpia familia) i sòcio-econòmics generals. En el nostre cas. això implica la relació dels mecanismes d’herència amb la conjuntura de mercat i de les possibilitats de comercialització de la pròpia collita. amb les necessitats d'equilibrar els recursos humans amb la producció.

\section{Els Fabregat}

\section{Els Fabregat, casa i terres}

La familia estudiada no viu actualment a Gratallops. Les seves terres han estat en part venudes $i$ en part semiabandonades. mentre que la seva casa no serveix més que per passar-hi els estius. La nostra reconstrucció genealògica i d'evolució del patrimoni comprén un dels grups «Fabregat». durant el periode de temps que aquesta familia va anar constituint les seves propietats, fins a la seva desintegració. A grans trets. era una familia de propietat mitjana, que va arribar a tenir. durant l'últim quart del segle XIX i primer del XX un patrimoni important. a l'entorn de les $30 \mathrm{Ha}$. de terres $i$ amb els elements necessaris per a la producció del vi. els seus propis cups. Dins del poble seria definida com a una familia benestant. que necessitava de jornalers i parcers per al conreu de les seves terres $\mathrm{i}$ mantenia bones relacions de parentiu amb les families més riques del poble.

El seu patrimoni va anar incrementant-se fins el 1880 . Excepte la casa $i$ unes parcel-les que es mantenen fixes i que passaran d'un a altre hereu. les altres parcel-les mostren una mobilitat considerable. amb terres que seran transmeses als altres fills o a d'altres que s'incorporaran al patrimoni per via de l'aliança matrimonial. Els quadres 2 i 3 representen. respectivament. l'evolució genealògica $\mathrm{i}$ patrimonial $\mathrm{i}$ ens permeten veure com. mitjançant diverses aliances matrimonials. van consolidant $i$ ampliant llur patrimoni. Les propietats que, en un moment o altre pertanyeren a la familia eren les seguents:

Casa: Va ser construida a mitjans del segle XIX. en un moment en què la familia havia crescut en quant al seu nombre de membres $i$ en què la seva posició havia arribat a ser benestant. Per aquestes raons. la casa seria gran. constant de planta baixa $i$ de tres pisos. A la planta baixa. comptava amb tots els elements necessaris per a la producció própia de vi (cup. celler. estable. etc.). mentre que la primera i segona eren dues vivendes amb tots els elements necessaris per a una vida autonoma a cada planta (cuina. menjador. llar de foc, etc.). Aixi. malgrat compartir la mateixa casa i treballar en comú les terres. l'estructura de la vivenda permetia una vida gairebé separada per a dos grups (a la casa varen arribar a viure nou persones).

Parcel-les:

1. «Dona Gambosa». Va ser la parcel.la mitjançant la qual va constituirse la propietat. El 1798 era repartida. assignant-se a en Pau Fabregat (veure quadre genealògic) una donació de 5 jornals per part del seu germà gran. Limitava, doncs. amb les parcel.les dels altres germans, però no hem pogut 
identificar la seva situació. ni tampoc fins quan va ser propietat de la familia (ja no consta en el Testament del mateix Pau Fabregat).

2. "Tros de Dalt». Ha estat la parcel.la básica de la familia. Malgrat la seva llunyania (més d'una hora de cami a peu). ha estat sempre transmesa a Thereu principal de la familia. junt amb la casa. criteri de succesio que s'ha mantingut fins avui. Es una parcel.la de $6 \mathrm{Ha}$.. tota ella de secà $\mathrm{i}$ amb força pendent. Totalment plantada de vinya fins a la fil.loxera. després daquesta només va replantar-se en un $70 \%$. mitjançant contractes de parceria. Posteriorment. ha anat minvant progressivament en les seves collites, fins a deixar de cultivar-se totalment a partir de 1975. Superficie: $5 \mathrm{Ha} .58$ a.

3. «Miloguera». Va incorporar-se als Fabregat grácies a lherència de la familia Porrera a la seva vidua Magdalena Fabregat el 1855. qui la transmeté al seu nebot. Gràcies a aquesta herència. com veurem. els Fabregat varen rebre un fort increment patrimonial que va fer-se efectiu el $1906 \mathrm{amb}$ la mort de Magdalena Fabregat. però que de fet ja abans seria conreada. Aquesta era una parcel.la de mitjana extensio que seria venuda cap al 1930 . quan la familia va deixar de residir al poble.

4. «Masos de Falset» o «Mas». Dins del terme de Falset. però més a prop de Gratallops i també de secà. Va seguir la mateixa evolució que l'anterior.

5. "Vellvisos". Parcel-la de regadiu i secá. sobre tot. prop del terme de Porrera. part també del patrimoni de Josep Porrera. peró venuda poc després que el seu nebot Anton Fabregat la rebés en herència (1906).

6. "Trosset». Petita parcel-la de vinya de 9 a.. que també es rebé de part d'en Josep Porrera.

7. "Collet». Va incorporar-se al patrimoni familiar mitjançant un matrimoni. amb Narcisa Auqué. el 1884. Es una parcel-la propera al poble (a menys de deu minuts). fertil i gran. Cap al 1930 seria partida i s'en vendria una part (aproximadament la meitat) a un familiar proper. Estava totalment plantada de vinya fins a la fil-loxera (amb algunes figueres $\mathrm{i}$ atmetllers). Superficie: $6 \mathrm{Ha}$.

8. "Torrent». Es de regadiu i uns pocs ceps. Era més que res una horta per al cosum familiar. Era també procedent de l'herència de Josep Porrera. Superficie: 67 a.

9. "Costa». Peça de secà. incorporada per segones núpcies el 1818. essent propietat de la familia fins el 1945 . Superficie: 51 a.

10. «Hort Pas del Camp" o «Hortet Cami del Camp". Petita horta de regadiu. d'unes 4 a.. transmesa des del $1840 \mathrm{com}$ a horta per al consum familiar. Superficie: 4 a.

11. "Hort del riu» o "Hortet". Com l'anterior. petita horta de regadiu tocant el riu i propietat dels Fabregat des de mitjans del segle passat. segurament per compra. Superficie: 4 a. $50 \mathrm{ca}$.

\section{Constitució del patrimoni (1798-1856)}

La primera meitat del segle XIX va estar condicionada. al Priorat. per dos fets importants: una gran expansió viticola i la desamortització dels béns de la Cartoixa de Scala Dei. L'augment constant dels preus, pel fet que l'excedent de vi era fàcilment venut al mercat americà. del nord d`Europa i de França, foren un estimul per a la plantació de nombroses parcel-les (abans bosc) més enllà de les possibilitats dun bon conreu i de la força de treball disponible. Amb un rendiment minim de les vinyes (a causa de les característiques de les terres poc adequades $\mathrm{i}$ diuns conreus 
deficientes). un sistema aixi només podia fonamentar-se en uns jornals molt baixos i uns contractes de parceria amb unes condicions de sobretreball. D’altra banda. la desamortització va possibilitar l'accés d'una burgesia inversora. que accedi sobre tot a la compra de terres al terme de La Morera. on quatre propietaris comprarien la majoria de les terres de la Cartoixa.

En aquestes circumstàncies, a Gratallops anà constituint-se una classe de propietaris locals, que aconseguirien importants patrimonis sobre tot gracies a les aliances matrimonials $i$ a la rompuda de noves terres. Aquesta classe. però. realitzà una expansió viticola amb molt poques inversions economiques. Junt amb aquesta classe. que esdevindria hegemònica sobre tot durant l'època de la Restauració gràcies a l'accés al control polític. sorgi un grup de propietaris mitjans que aconseguirien mantenir-se gràcies a la força de treball pròpia i a l'increment del seu patrimoni per la via de l'aliança matrimonial. Aquest és el cas de la familia Fabregat. El 1792. en Pau Fabregat (quarta generació des de que el primer Fabregat arribava a Gratallops) i la seva muller Rosa Axonch havien mort deixant al seu fill Anton una ja important herència de prop de $18 \mathrm{Ha}$. L'Anton convivia. a més de la seva dona, amb els seus tres germans menors (Pau. Joan i Antònia). a la casa que els pares també li deixaren, al carrer de Baix. A més de la seva ja bona posició economica. l'Anton mantenia un bon status dins del poble: era regidor a l'Ajuntament i formava part d'una societat de propietaris.

Per consolidar la seva posició havia de procurar un matrimoni satisfactori per als seus germans menors. En efecte. les terres no eren. malgrat tot. prou grans per mantenir-los a tots o repartir-les. per la qual cosa calia integrar els seus germans a d'altres families propietàries amb terres per cultivar. Aquest seria el sentit del matrimoni de Pau Fabregat amb Maria Ros. En Pau, de més de 30 anys, es casava amb una filla única molt jove. tot just adolescent. $\mathrm{i}$ hereva de la casa $\mathrm{i}$ terres dels seus avis. En Pau anava a viure amb la familia de la seva dona. junt amb els avis d'aquesta. car la seva mare (hereva) havia mort $i$ el seu pare ben aviat es tornaria a casar $i$ aniria a viure amb la seva nova muller. En aquest sentit. En Francesc Reig (avi) preferiria trobar una sol-Iució a la seva succesió que passava. necessàriament. pel matrimoni de la seva néta. amb algú que pogués fer-se càrrec del conreu de les seves terres, conreu que en aquell moment estava a carrec del seu gendre, vidu de la seva filla.

Els Capitols matrimonials subscrits definien perfectament les característiques de l'aliança $i$ de l'herència i el pacte entre ambdues families. Del seu gemà Anton Fabregat, en Pau rebria una parcel.la important (de 3 Ha.). «Dona Gambosa», 150 lliures en diners i la seva roba d'ús. patrimoni que constituia l'aixovar aportat a la familia de la seva dona:

«Anton Fabregat del sobredit lloch de Gratallops. germà del citat Pau Fabregat. atenent que Pau Fabregat y Rosa Axonch conjugues sos difunts Pares ja havien consumit la part de reserva que se reservaren quant feren donació universal al mateix Anton. pero com este desitja que son Germà logri un acomodo corresponent, y també per apartar entre ells tots litigis $\ddot{y}$ discensions han convingut unanimas y conformes que lo sobredit Anton (...) de sa libera y espontanea voluntat per ell y sos hereus $\ddot{y}$ succesors dona (...) 
al mateix Pau Fabregat son Germa (...) tot aquell bosí de viña ï Arbres plantat Dona Gamosa (...) Item la cantitat de cent cinquanta lliuras ab diners: y finalment la roba de son us y post. dotse camisas entre ellas una de tela. dos llansols de tramat. dos cuixineras. sis tovallons de cotó $\ddot{i}$ fil. $\ddot{i}$ dos paños (...) Lo sobrenomenat Pau Fabregat fent estas cosas de espres consentiment. a voluntat de son germà constitueix y en aixocar seu aporta a la sobredita Maria Ros Donsella. Francisco Retx i Maria Anguera. muller $\ddot{y}$ avis respectivament tot quant sobre si es estat donat per dit son Germà volent que en virtut de los pactes. dita sa esdevenidora muller $\ddot{*}$ Avis cobren. tingan $\ddot{y}$ posehescan tot son dot lo temps que dit Pau Fabregat estara en sa Casa compañia invertirlo en pagar mals $\ddot{i}$ deutes de la mateixa Casa. $\ddot{Y}$ en millorar sos Bens (...) La espresada Maria Ros y sos Av is fan y firman la Carta Dotal. y de aixovar (...) tot lo que li asseguran sobre tots sos bens $\ddot{i}$ li prometen restituir y tornar sempre i quant se separi de sa casa y compania. ó sempre que aja restitució de dot $\ddot{y}$ aixovar (...) Pau Fabregat accepta la constitució dotal feta per dita Maria Ros a son favor (...) ÿ per la qual. per sa lloable virginitat li fa de creix aument ó donació per noces de la cantitat de cinquanta lliures Barna(...)m.9

Tanmateix. el patrimoni essencial seria l'aportat per la familia de Maria Ros, sobre tot la parcel.la del «Tros de Dalt». que el seu avi havia comprat. i que serà la més important del patrimoni de la familia. sempre rebuda per l'hereu principal. Encara. en el moment de la transmissió. les terres estaven dins d'unes relacions d'emfiteusi respecte a la Cartoixa de Scala Dei. per la qual cosa en Pau Fabregat s'obligava al pagament de 100 lliures per raó de la transmissió i 3 lliures annuals per «raó» de la terra». a la vegada que s'hipotecava la terra com a garantia del pagament.

Siniciava aixi, el patrimoni i la historia de la familia estudiada. Mitjançant el matrimoni, i aplicant una sol.lució especifica per aquell moment. en Pau tenia un patrimoni suficient per al conreu i començava a consolidar la seva posició. A part de l'herencia dels seus avis. Maria Ros rebria més tard en herència una parcel.la del seu pare. el que definí ja una propietat al limit de les possibilitats humanes de la familia. havent-se de recórrer a la mà d'obra jornalera.

En Pau viuria forces anys. fins el 1842 (la seva casa seria anomenada. posteriorment. la "casa de l'avi Pau Fabregat»). Si en el seu primer matrimoni en Pau havia pogut crear un patrimoni suficient. el sentit de la seva oportunitat matrimonial seria encara més evident en el seu segon matrimoni. La seva dona Maria Ros moriria només deu anys després del matrimoni. deixant un sol fill. l'Antoni Fabregat. quedant el seu marit com a usdefructuari de les seves propietats. car els seus avis també havien mort. El 1818. en Pau Fabregat es casava amb la vidua Antònia Auqué que. a la seva vegada era usdefructuària d una parcel.la rebuda del seu difunt marit. La Costa. D'aquesta manera. Pau Fabregat aconseguia tenir quatre parcel.les (Tros de Dalt, Coll. Dona Gambosa i Costa). gràcies als seus dos matrimonis. Tanmateix, tant ell com la seva nova dona no eren més que usdefructuaris d'aquestes terres, que havien de ser transmeses als seus respectius fills. El patrimoni, es consolidaria amb el matrimoni dels respectius fills. només set anys després del dels seus pares. En efecte. el 1825. Antoni Fabregat Ros, fill d'en Pau i Maria Ros. es casava amb Magdalena Vernet Auqué. filla d'en Miquel i de l'Antònia Auquè. ara 
casada amb Pau Fabregat. Mitjançant aquest doble matrimoni. el patrimoni familiar quedava consolidat. precisament durant els anys en qué els preus del vi donaven uns resultats més favorables i milloraven les condicions de comercialització.

Malgrat això, Antoni Fabregat no tindria recursos suficients per a la compra de més terres. Les actuals. el permetien mantenir una posició economica mitjana. envejable per a molts petits propietaris que només podien subsistir com a jornalers, però sense possibilitats d'una inversió que augmentés les seves terres. Entre daltres coses. la casa estava mancada d'una força de treball suficient. com pot veure's al quadre num.3: mort el seu pare. només ell treballaria les terres. Els seus esforços anirien sobre tot a la construcció d'una nova casa: aquesta representava no només unes millors condicions de vida i una posició de major prestigi. sinó. sobre tot. la possibilitat de conviure un major nombre de persones. i. en consequència. una major força de treball.

\section{Increment patrimonial (1855-1884)}

Lincrement patrimonial hauria de realitzar-se també gràcies a nous matrimonis i aliances. En aquest sentit. els matrimonis realitzats pels fills d'Antoni Fabregat permetrien incrementar el seu patrimoni en un $150 \%$. El 1856. el seu primer fill. Antoni Fabregat Vernet es casava amb Maria Ros Torné. cosa que també implicava reforçar l'aliança amb la familia Ros. En aquest matrimoni, mitjançant els capitols matrimonials subscrits poc abans de celebrar-se. en Antoni Fabretat era nomenat hereu. rebent la donació postmortem dels seus pares de la majoria de les propietats (Tros de Dalt. Costa i el terreny on el 1863 s'hi construiria la casa familiar). La seva dona rebia una dot de 1.000 lliures. a més d'una bona quantitat de roba i mobles. El document resulta interessant per la descripció dels béns mobles i roba pagats com a dot, aixi com del procés de pagament:

«(...) otorgan y consedeixen á la mateixa neta y filla present $y$ als seus en pago y satisfacció per tot dret de llegitima paterna y materna. simplement de ella. part de creix. deixa a ella feta per sa difunta mare en son últim testament (...) la cantidad de mil lliuras moneda barna. esto es 500 lo dit Francisco (avi). 250 lo predit Llorens (pare) y las restants per lo que conté la relatada deixa (...): bancs y posts de llit. márfega. matalás. colxa. coixins y dos llansols. 18 camisas de bri. 8 parells de coixineras. 12 tovallons. 9 anaguas. una mantellina de franela. una caixa. una calaixera y la roba de us y port de son fadrinatge. Pagador 400 lliuras roba y llit lo dia de 10 esponsori. de dit a un any 200 lliuras y aixis cada any igual cantitat en dit dia hasta son pago $(\ldots.) .{ }^{\text {io }}$

Posteriorment, en morir els seus pares. Maria Ros rebria una petita parcel.la prop del riu. dedicada al conreu de l'horta i denominada precisament "Hortet», com a consequència d'una disputa entre els marits de les tres germanes Ros (entre ells. Antoni Fabregat).

De totes maneres. la part més important de lincrement patrimonial familiar arribaria mitjançant un altre matrimoni. celebrat un any abans. el 
1855. Aquest any, Magdalena Fabregat Vernet. germana d'Antoni. es casava amb Josep Porrera, encara menor d"edat però hereu dels seus pares. Josep Porrera i Teresa Auqué. que havien mort feia pocs anys. deixant-li un bon patrimoni: una casa. una parcel.la de regadiu i tres parcel-les de vinya. El matrimoni possibilitava una bona posició per a Magdalena Fabregat, a més de repetir un altre matrimoni amb els Auqué: en Josep Porrera i Magdalena Fabregat eren cosins segons. Tanmateix. una sèrie de fets biològics determinarien que tot el seu patrimoni passés als Fabregat. El matrimoni Porrera-Fabregat només tindria un fill que moriria durant el primer any de vida. i en Josep Porrera moriria el 1883. En aquesta data, la seva dona rebria l'herència de les terres dels Porrera $\mathrm{i}$ tornaria a viure amb els pares i germans. tot portant una important herència que. a partir d'aquella data seria cultivada pels Fabregat.

Durant aquest període, les condicions no eren però tan bones per al camp. Entre el 1857 i 1877 es produeix una primera crisi viticola. molt menor que la següent de la fil.loxera. però que suposaria unes pèrdues demogràfiques importants a Gratallops. en què la població passaria de 1.177 habitants a 903 habitants, és a dir un 23\% de pèrdues. El 1865 la collita va perdre's gairebé del tot: en cavi. el 1871 seria excel.lent. però el 1874 s'iniciarien, amb l'anomenat «aiguat de Santa Tecla», uns anys de males collites fins el 1877. La visió. doncs. que donen la majoria d'historiadors. indicant que aquesta és una època d'abundància per a la vinya. caldria matisar-la, ans al contrari no s'expliquen les importants pèrdues demogràfiques. Un dels emigrants fou en Jaume Fabregat. que el 1864 marxava cap a Barcelona. Aquesta primera emigració incidiria més en el procés de constitució de families de propietaris importants, que concentraven cada vegada més terra.

A partir d'aquest moment. la familia tendeix a comportar-se com a familia benestant. Malgrat comptar a la pròia casa amb una important força de treball (quatre homes adults). s'hauran de subscriure diversos contractes de conreu i la feina a jornalers era destacada. Llorenç Fabregat seria regidor de l'Ajuntament i tenia un status considerable al poble. Però a més. la familia incorpora unes normes hereditàries molt més d'acord amb la seva classe. tendent sobre tot al manteniment unitari del patrimoni. això vol dir que les reparticions i. en consequència. la circulació de terres és menys frequent. Aixi. per exemple. en el testament d'Antoni Fabregat. mort el 1878. es deixa tota la propietat al seu fill Llorenç mentre els altres fills rebran ben poc:

«D. Antonio Fabregat Ros. casado. propietario de esta vecindad é hijo legitimo y natural de los difuntos consortes Pablo y Maria. hallándose en cama algo indispuesto pero con claridad de potencia ! del habla. queriendo disponer de los bienes para después de su muerte. otorga testamento de la forma siguiente:

- Nombra albacea a su esposa Da. Magdalena Vernet. a cuya dirección! voluntad deja lo referente a su entierro y sufragios.

- Lega a su hijo Jaime Fabregat Vernet la cantidad de cuatrocientas libras equivalentes a mil sesenta y seis pesetas setenta y seis céntimos: cuyo legado se le satisfará en cuatro plazos anuales de igual importe. 
- Lega a su otro hijo Sebastián Fabregat Vernet la cantidad de doscientas libras (...)

- Lega a su hija Magdalena Fabregat Vernet la cantidad de siete pesetas en atención a que ya tiene anticipada la legitima. y faculta a la misma para disponer de ciento trenta pesetas a más de la cantidad que se le señaló libre en sus capitulos. ?

- Lega el usufructo de todos sus bienes y derechos a su nombrada esposa Magdalena Vernet por mientras permanezca su viuda.

- Y en todos sus restantes bienes y derechos instituye heredero a su otro hijo Antonio Fabregat Vernet. ${ }^{11}$

Els anys pitjors de la crisi (entre el $1859 \mathrm{i}$ el 1866) coincidiren amb el naixement dels tres fills d'Antoni Fabregat (Llorenç. Consolació i Jaume) i els de la construcció de la casa del carrer de la Font. A casa hi viurien nou persones, de les quals, com s'obseva al quadre 3 , tres eren homes adults amb capacitat per treballar la terra. Malgrat tot, eren necessaris jornalers (els dies de major treball: poda, verema, llaurada, etc.) i algunes terres es contractarien en parceria. Amb la casa, però. la familia havia aconseguit disposar d'un ampli espai per a l'elaboració del vi (cup. cellers, etc.).

\section{Màxima expansió (1884-1917)}

Els anys d'una extensió patrimonial i productiva més important coincidiren amb la darrera etapa d'expansió de la viticultura, entre el $1877 \mathrm{i}$ el 1893. Anteriorment a l'arribada de la fil-loxera al Priorat (detectada a Gratallops el 1893, però afectant la vinva especialment a partir del 1896). els preus del vi pujaren considerablement com a consequència de la demanda de vins des de la França ja afectada per la fil.loxera i de les zones afectades a Catalunya mateix. En aquestes circumstancies, serien les grans families les que obtindrien uns beneficis més importants, mentre la situació dels rabassaires empitjorava i la seva confrontació augmentava.

El 1884, en Llorenç Fabregat Ros, hereu d'Antoni Fabregat Vernet, es casaria amb Narcisa Auqué, obtenint dispensa eclesiàstica de tercer grau. Aquest matrimoni va permetre arribar a assolir la màxima propietat de la familia. amb l'herència, per part de Narcisa Auqué. d'una bona parcel.la (gran. fèrtil i propera al poble), el Collet. Un any més tard, el 1885. la vidua Magdalena Fabregat tornava a viure a Cal Fabregat, com hem dit, amb tot el seu patrimoni: una casa (al carrer Consolació), una parcel.la de regadiu (Torrent) i quatre parcel.les de vinya (Els Masos, Vellvisos, Troset i Miloguera). Si bé les parcel.les no passarien a ser propietat plena d'en Llorenç Fabregat fins a la mort d'aquesta, el 1906, ja des d'aquest moment serien administrades $\mathrm{i}$ cultivades per la familia estudiada.

La situació de la família era, doncs, pujant. En Llorenç Fabregat havia arribat a aplegar sis parcel.les de vinya, dos horts i tres cases a Gratallops. A la vegada, la posició d'en Llorenç Fabregat al poble era de força prestigi, arribant a ser regidor i mantenint relacions de parentiu amb la principal familia local. Mentrestant, a la casa hi convivien un grup familiar de deu persones. de les quals quatre eren homes adults que podien treballar la terra. En aquest sentit, els anys de màxima expansió de la comercialització coincidirien amb el d'un funcionament de la familia Fabregat més d'acord amb els models normatius ideals, models que serveixen a una classe per al 
manteniment del seu status. La família extensa es fa especialment útil en aquests moments. però és també possible a causa de la superficie de terres i de la producció que generen; si no fos aixi esdevindria inviable. Per això. el model de familia extensa en una economia fonamentada en el monoconreu. com a Gratallops, és només possible en el context de les families de propietat mitjana o gran.

Els Fabregat tindran relacions de parentiu amb les grans famílies locals. i n’adoptaran alguns comportaments. A més de l'activa participació politica en la vida local (Ajuntament. els seus noms són sempre presents en les meses electorals. essent diverses vegades compromissari per a l'elecció de Senadors. i més endavant en les Cooperatives i societats recreatives) en la seva organització domèstica adopten les pautes corresponents a aquesta classe. Dedicats els homes al conreu de la vinya, en part a l'administració i elaboració del vi en aquelles parcel.les sotmeses a contractes de parceria. les dones de la casa mai anirien a treballar a la vinya. ni en les ocasions de treball més intens. restant dedicades per complet al treball domèstic. A més. aquest tipus de families desenvoluparien més contactes amb l'exterior que els petits propietaris. realitzant viatges. rebent la premsa, contactant majoristes per a una millor comercialització del vi. assistint als mitings de propietaris i agricultors impulsats per la Lliga. durant el primer quart d'aquest segle. o per exemple assistint als famosos viatges a la capital provincial per a l'elecció de senadors a l'època de la Restauració.

La crisi de la fil-loxera no va afectar massa. d'immediat, aquest ritme de vida. Detectada el 1894, quan n'Antoni Fabregat encara vivia i en Llorenç Fabregat ja tenia els seus dos fills. la fil.loxera acabaria en cinc anys amb la majoria dels ceps de la familia Fabregat. Els Fabregat només aconseguirien refer-se parcialment. Inciarien ben aviat la replantació amb ceps americans, resistents a la fil.loxera. començant pel Collet. la parcel.la més propera i de millor qualitat que es tenia en aquell moment. però. les parcel les més llunyanes anirien replantant-se amb molta lentitud. El "Tros de Dalt", més llunyana, trigaria més en ser replantada i només parcialment. Encara el 1917, el «Tros de Dalt» s'havia replantat només en una proporció molt petita. D'altres, com els "Masos de Falset», ja no es tornarien a replantar mai més.

La replantació era lenta. però, els mercats tampoc no admetien ja tant de vi i els preus havien baixat considerablement. La població a Gratallops disminui substancialment: mentre que entre $1877 \mathrm{i}$ el 1887 havia augmentat (de 903 a 984 habitants). entre aquesta darrera data i el 1910. la població quedà en 662 habitants. Només els anys de la I Guerra Mundial representaren una certa estabilització, abans d’entrar en una crisi permanent. que mai més seria superada. La crisi posà en evidència. també. les condicions de repartició de propietat. i. com a consequència de l'emigració disminuirien les possibilitats de braços disponibles. La confrontació entre classes s'accentuaria especialment i, en definitiva, els jornals pujarien considerablement. 


\section{Lenta desintegració de la propietat (1917-1939)}

Les circumstàncies indicades incidirien de manera considerable en la familia Fabregat. Coincidint amb la crisi del 1917 i el final de la I Guerra Mundial, diversos fets canviarien el curs de la història dels Fabregat. La familia no comptava, en aquells moments, amb força de treball suficient a nivell familiar (només en Llorenç Fabregat i el seu fill Llorenç Fabregat) en uns moments en que la necessitat de braços era important. (els anys de la replantació) si la propietat volia recuperar-se. L'única sol.lució fou contractar la majoria de les terres amb parcers, encara en condicions de mitgeria. Especialment significativa va ser la signatura del contracte de parceria del "Tros de Dalt», amb Miquel Caballé. de Gratallops. que s"obli- gava, a més del conreu de la terra i de l'entrega de la meitat de la collita. a la replantació anual de la vinya:

«(...) bajo los pactos siguientes: vida.

1. - Miguel Caballé disfrutará de la medianeria o «mitjé» durante toda su

2. - Cultivará la tierra a uso y costumbre de buen labrador. debiendo el dueño de la finca entregarles todos los barbechos que el Caballé le pida para plantar.

$3 .^{\circ}$ - Caballé se obliga a la conservación de todos los árboles existentes y para el arranque y plantación de los que comienza necesita el permiso del dueño.

4. - No podrá sin permiso del propietario y medianero apacentar en la tierra de referencia ganado de ninguna clase.

5. - El Caballé viene obligado a plantar por lo menos cincuenta barbados americanos cada año.

6.․ Si el Caballé faltase al cumplimiento de alguno de estos pactos. podrá ser removido, sin que pueda alegar en su favor excusa alguna. salvo enfermedad. que si esta es crónica y no puede trabajar o hacer trabajar la finca se entenderá que renuncia.

7.0- Que cumpliendo todo lo pactado Caballé pierde al morir todo derecho y renuncia al mismo (...)., 12

El mateix 1917. en Llorenç Fabregat feia testament dividint les seves terres entre els seus dos fills (fill i filla). La divisió podria semblar contradictoria d'acord amb el que venien fent les darreres generacions dels Fabregat, peró sembla ser una nova estratègia d'adaptació a les condicions sòcio-econòmiques presents $\mathrm{i}$ a la pèrdua de rendabilitat $\mathrm{i}$ expectatives de les vinyes. Però, aixi i tot, responia a un intent de continuació de l'explotació. La divisió, però, no arribaria a fer-se efectiva més que legalment. El fill gran L1.F.A., emigraria a l'Argentina ben aviat. i totes les seves terres passarien a un règim de mitgeria. L'altra filla. E.F.A.. es casaria amb el mestre del poble el qual, a més de ser foraster i d'haver de canviar poc després de desti, no constituia cap garantia de continuitat de l'explotació. a causa de la seva professió. Malgrat viure alguns anys a Gratallops. el nou matrimoni no trigaria gaires anys en ser destinat a un altre poble. La propietat, doncs, va continuar treballant-se majoritàriament en règim de parceria. mentre els dos fills s'allunyaven del treball agricola. motivats per la manca d'expectatives de rendabilitat. 
La repartició de les terres pretenia encara donar-ne als dos fills la quantitat necessària per a continuar una explotació. El fill gran rebia les terres que havien estat de la família durant més temps ( Camp d'en Piquén, sobre tot), mentre la filla rebia. apart de la casa. les millors terres ( Collet», aquesta transmessa per la seva mare). En tot cas, però. tambẻ pretenia donar a cada un una posició que no s'havia assolit mitjançant matrimonis. En el fons, però, la qüestió essencial és la redabilitat i expectatives de les terres. Es el darrer cami d'una classe de propietaris que. a partir d'ara, mantindran l'explotació de les terres només mitjançant contractes de conreu. mentre ells viuran fora del poble.

Mort en Llorenç Fabregat Ros. les terres heretades pel seu fill resident a America. serien cedides per aquest mitjançant escriptura notarial des d'Argentina a la seva germana, perquè aquesta les administrés. comprés o vengués. Aixi va fer-se. De les cinc propietats d'en LI. F.A., quatre foren venudes. especialment a parents propers, a excepció del «Tros de Dalt», que la mateixa germana va comprar per ella. I de les cinc propietats d'E.F.A., una fou venuda («Els Masos») i una altra («El Collet») seria partida i venuda parcialment a un parent proper. La propietat quedava aixi extraordinàriament reduïda. però l'operació de venda no suposaria uns ingressos considerables: el valor de la terra era cada vegada menor. Des de llavors, l'explotació es mantindria totalment en règim de parceria, al terç, i la producció de vi deixaria de fer-se a la pròpia casa, fent-se socis de la Cooperativa i portant-se allà. La producció encara serà important fins els anys cinquanta. però aquesta ja no era el mitjà de vida dels seus propietaris.

\section{Propietat testimonial}

Poc a poc, les terres anirien perdent-se. Els contractes de parceria mantindrien l'explotació fins als anys 60. ara en condicions molt més favorables per als parcers. L'explotació ja no representava. però, una font d’ingressos econòmics: per aixó l'anomenem upropietat testimonial». A partir de mitjans dels 60 , Gratallops tornaria a veure incrementar el seu ritme d'emigració. Els més afectats tornaren a ser els petits propietaris. produint-se d'aquesta manera una manca de gent que volgués treballar fora de les seves propietats. Els que quedaren. es dedicaren a explotar les seves própies terres, $\mathrm{i}$ com a molt a fer de jornalers en determinades feines (llaurar, cavar, veremar, etc.), mentre el règim de parceria pràcticament ha anat desapareixent. Les terres de la familia deixaren també de ser cultivades pels parcers, essent treballades llavors per llurs propietaris que anirien a podar-les els caps de setmana, i a recollir el raïm (la verema) durant les vacances, mentre el llaurat, ensofrat i moltes veremes es feien per jornalers. Com pot entendre's, aquesta situació portà ràpidament a una disminució de la producció de les vinyes que anả agreujant-se amb la difícultat de trobar jornalers, especialment a partir dels anys 70 .

Les terres cultivades aixi, amb una poda insuficient i mal feta, i molts anys sense les llaurades o l'ensofrat adequant. han anat perdent-se. Avui en dia. totes les terres són improductives. com a simbols d'unes explotacions viables dins d'unes altres condicions sócio-econòmiques. La casa, 
d'altra banda, ha canviat la seva funció: d’explotació agricola a residència pels caps de setmana i vacances. Moltes d'altres terres i cases han seguit, a Gratallops, un cami semblant.

\section{Transmissió de la propietat i models de parentiu}

A partir de l'estudi d'aquest cas concret. no voldriem extrapolar una sèrie de conclusions de caràcter general, perquè cauriem en el risc de donar com a vàlides unes constants que tenen un caràcter particular. Tanmateix, i tenint present una contrastació d’aquestes pràctiques diferencials amb els aspectes generals observats en la nostra recerca (Roigé, 1984), ens permetem algunes conclusions i reflexions sobre la natura del mateix model domèstic, les pautes i estratègies hereditàries, i, sobre tot. d’adequació d'aquestes institucions als processos més generals del context social.

En primer lloc, resulta evident que el model d'herència i família troncal a l'entorn de la casa o masia propi de la Catalunya Vella, i que a vegades ha volgut generalitzar-se, és inadequat per a l’ámbit geogràfic de la Catalunya Nova. o com a minim, només és vàlid per a les seves families amb propietats importants. Al marge dels problemes metodològics i teòrics que aquell model presenta i de la seva necessària revisió (Comas d’Argemir, 1984:65), és clar que les recerques sobre la Catalunya Nova troben uns problemes suplementaris per la manca de perspectives de caràcter general. Així i tot, creiem que caldria anar amb compte a l'hora de formular models domèstics i d'interpretar normatives globals, atemporals (o, el que és el mateix, definir una dualitat d'interpretacions: tradicio$\mathrm{nal}$ (canvis moderns) i d'aplicació al conjunt de families camperoles.

El model domèstic, les normes ideals culturals, per les quals ha semblat guiar-se la familia Fabregat i d'altres de la seva mateixa posició, no és més que la legitimació d'un conjunt de normes i representacions pròpies de la seva classe (Assier-Andrieu, 1984:23) i que tenen com a funció essencial la legitimació de la seva posició social i la regulació de la transmissió de la propietat privada desigualment repartida. Les estratègies, les reglamentacions juridiques, els ideals normatius, la composició del grup familiar i altres aspectes que configurarien un «model», aixi com la mateixa funcionalitat de les diverses institucions que el constitueixen, són aspectes que es presenten de forma diferencial en una $\mathrm{i}$ altra classe $\mathrm{i}$ que dificilment podem generalitzar a no ser que sigui a nivell ideològic. Aixi, per exemple, la institució de la dot, mentre que per a les classes benestants representa un mode de defensa de l'explotació agricola i la seva propietat, impedint la seva fragmentació en explotacions menys productives en evitar els matrimonis entre membres de classes diferents. en les classes subordinades és un cami d'empobriment que dificulta la mobilitat social (Tentori, 1976:283-284). El més coherent, doncs, si no volem caure en representacions idealistes sobre pretesos models tradicionals de parentiu (com a abstracció de la realitat que, a més, oblida sovint els aspectes conflictius i la funció essencialment política del grup domèstic), és adoptar una pers- 
pectiva històrica i un intent de descriure i dibuixar lorganització sociocultural especifica dels diversos tipus de familia (o. si es prefereix. classes socials). explicant la seva posició dins del sistema total.

La perspectiva històrica. entenent que els processos socials no són repetits de forma idèntica i que les societats estan continuament canviant. és essencial. En el cas dels Fabregat. lexemple ens demostra que la concreció pràctica de les normes d'herència mostra en cada circumstància una gran flexibilitat i capacitat d'adaptació. La composició del grup familiar, i els propis criteris de succesió, procuren adaptar-se a la conjuntura històrica, a nivellar les pròpies condicions i característiques de l'oferta de jornalers i parcers fora de l'àmbit domèstic. En definitiva. la familia tractarà d'adaptar-se als processos de canvis socials. decidint els mecanismes $\mathrm{i}$ herències més adequades per al manteniment de la seva posició i. quan sigui possible. l'increment patrimonial. Una perspectiva aixi implica la consideració de què els models de parentiu no només han canviat en els darrers anys, durant els quals la intensificació dels trets empressarials, els ingressos fora de l'explotació agricola familiar i els majors contactes amb el món exterior haurien canviat la familia tradicional rural. amb una difuminació dels trets que la separen de la urbana (Galeski. 1977:248250). sinó que en cada moment. l'estructura i estratègies familiars han estat canviants, en una dialèctica d'adaptació a les condicions sòciohistoriques.

Indicàvem també la necessitat de dibuixar l'organització diferencial dels diversos tipus de familia. Families benestants i families subordinades actuen amb criteris diferents. La diferència essencial és que les primeres han d'assenvalar els mecanismes imprescindíbles per a la transmissió de la propietat. mentre els segons han de tractar sobre tot de reproduir la força de treball. La mateixa grandària del grup domèstic està condicionada pels recursos economics, per l'espai de la vivenda. I aixó ens suggereix tota una sèrie d'hipòtesis sobre les quals estem treballant: Seria possible establir una correlació entre la grandària de les explotacions i la grandària del grup familiar? La repartició de la propietat aixi sembla condicionar-ho: és possible la convivència d'un grup molt ampli de persones quan no hi ha una minima seguretat economica? Jornalers i petits propietaris hauran d’adaptar el nombre dels seus membres. desdoblant-se quan convé (mitjançant matrimonis), per aconseguir un major equilibri entre el nombre d'homes adults (que treballen al camp i aporten ingressos econòmics) i el nombre total de membres d'aquella familia. La convivència d'un elevat nombre de persones, en un sistema d'agricultura dedicada al comerç. es fa possible en la mesura que les explotacions són suficientment grans com per ocupar les possibilitats de treball dels homes adults del grup. per permetre el manteniment del conjunt dels seus membres i quan. per obvi que pugui semblar, la casa familiar és suficientment àmplia per permetre la convivència d'un nombre elevat de persones sense generar grans tensions. I no cal oblidar. respecte a aixó. que al Priorat. les cases de les families benestants eren dues o tres vegades més grans que les dels petits propietaris i jornalers. sovint força més petites. Els pares no podien imposar la cohabitació al seu fill casat més que quan estaven en condicions d'oferir-li una perspectiva suficientment bona d'herència. un patri- 
moni que pogués mantenir les dues families i una casa prou gran (Flandrin. 1978:116).

Aquest és el cas dels Fabregat. Quan arriben a tenir el maxim de persones co-residents és quan compleixen aquestes condicions. quan les seves propietats i casa són més grans. com pot observar-se al quadre núm. 5. Tanmateix, no ha d'oblidar-se tampoc que el grup familiar és més àmpli que el concepte de residència. En aquest sentit. la comunitat local estudiada inclou unes relacions de parentiu molt àmplies: a finals del segle passat. els Fabregat arribaren a tenir relacions de parentiu properes amb el $11 \%$ de la població local. Així, per a la definició del grup domèstic, concepte diferent al del grup de residència (Goody, 1958), no intervénen únicament factors de residència física. sinó també de reproducció, relacions socials. producció i reproducció i. en definitiva. el sentit de l'oportunitat en cada moment.

Per això. la conceptualització del factor temps resulta essencial. en permetre'ns estudiar el procés de la familia no en un moment precis i estàtic. sinó en el conjunt del seu desenvolupament. El cicle domèstic. com a un complex moviment que comprén des del primer matrimoni del cap de familia i els naixements resultants. els matrimonis d'aquests fins que l’últim resta a la comunitat domèstica. $i$ els naixements dels nens d'aquests descendents (Cuisinier, 1976:137), ens permet veure els processos de desenvolupament dels diversos tipus de grups domèstics i. sobre tot. la interrelació amb els factors històrics globals. En la nostra visió del cicle domèstic, en l'exemple que hem presentat. aquesta manifesta una evolució cíclica en què els caràcters significatius de la familia extensa i troncal apareixen en la majoria del seu procés. però dins d'una forma ciclica corresponent a diverses fases del seu desenvolupament. com ens mostra la gràfica seguent:
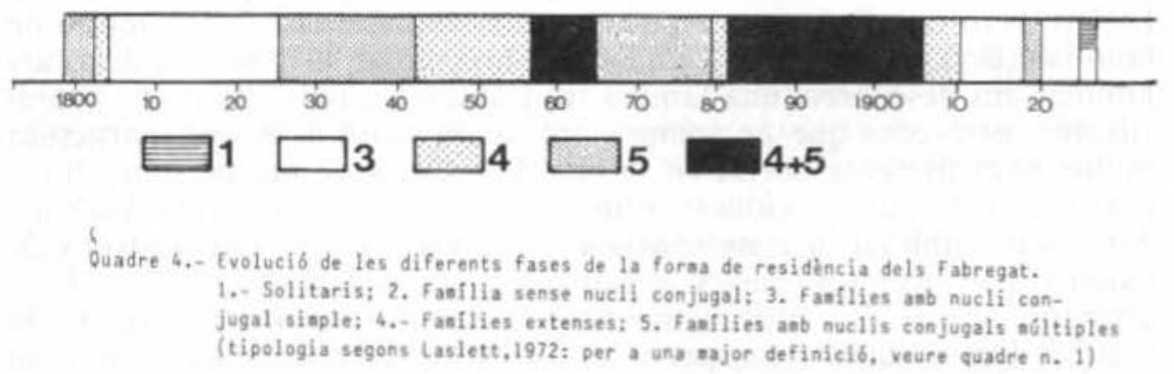
Més significatives, encara, per a la terminació d'aquest procés cíclic. són les conclusions que podem extreure del quadre núm. 5, que reprodueix totes les composicions familiars que han tingut els Fabregat entre $1798 \mathrm{i}$ el 1927, expressant els anys i causes de les seves variacions, així com el nombre de membres i la tipologia del grup segons la classificació de Laslett (1972:31).

Ambdós quadres ens suggereixen, sobre tot. dues grans constatacions. En primer lloc, la correlació entre les fases de major extensió del grup de residència $\mathrm{i}$ els períodes en què els Fabregat aconseguiren un major nombre de propietats. Com assenvalen Sieder i Mitterauer (1983:241), les característiques de la producció domèstica demanen una política de reproducció. establint un equilibri entre productors i no-productors. En definitiva. l'exemple de la família estudiada permet adonar-nos de la necessitat de no aillar el parentiu amb lleis pròpies. sinó com a una institució que ha d'estudiar-se amb un esforç de comprensió dinàmica i en constant diàleg amb el context general. Per nosaltres, i en el cas del Priorat. els "models» i "estructures» de parentiu i transmissió són diferents en cada classe social amb una tendència a adoptar en cada circumstància les estratègies més vàlides per al manteniment de la seva posició i. en definitiva, la legitmació socio-política a través d'un conjunt de normes i representacions d'un sistema desigual de transmissió de la propietat privada.

En segon lloc, i finalment, el darrer quadre permet veure la diversitat de composicions familiars que es donen en el curs de la història d'aquesta familia. En aquest sentit, estariem d'acord amb el que indica Berkner(1975:729-730), quan assenyala que les categories que Laslett assumeix com a estructures diferents (els tipus de ufamília» nuclear, extensa o múltiple), són en realitat fases diferents d'una mateixa estructura, un procés: «Aquest procés -ens diu Berkner- consisteix en una succesió de fases. cada una de les quals pot ser classificada segons les categories de Laslett. però cap d'aquestes en ella mateixa representa una estructura de familia” (Berkner, 1975:731). En l'exemple estudiat, la dinàmica dels curs familiar ens descobreix una familia troncal que va reproduint-se i evolucionant. però com que no sempre pot mantenir-se amb una estructura múltiple. es presenta sovint en la fase 4 (a causa de morts, sobre tot, i l'existència de vidus $\mathrm{i}$ vidues) o fins $\mathrm{i}$ tot en la fase 3 (familia nuclear). Aixó. sense oblidar la convivència en el mateix sostre d'altres tipus de parents molt diversos (oncles, germanes que retornen en quedar vídues, germans, nebots, ...), especialment en la fase de major expansió de la familia. Des d'aquesta perspectiva, la familia se'ns presenta com a un moviment dinàmic, "com a una ameba. que es reprodueix a ella mateixa, expansionant-se i contraent-se mitjançant una infinitat de moviments ciclics repetitius condicionats per l'edat, costums, mortalitat i recursos económics» (Stone, 1977:26). 
Arxiu d'Etnografia de Catalunya, $n^{\circ} 6,1988,60-86$

ISSN: 0212-0372. EISSN: 2014-3885

http://antropologia.urv.cat/revistarxiu

\begin{tabular}{|c|c|c|c|c|c|}
\hline |ands & Souriatis & $z$ & & $\frac{2}{2}$ & \\
\hline Irist-1100 & $\Delta-8, \ldots(0)$. & 4 & 4 & 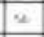 & $m$ \\
\hline wace-1keat & 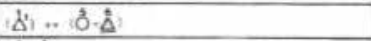 & 2 & & an: & $e$ \\
\hline isou-ities & 8 & 1 & 2 & $3 s$ & 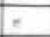 \\
\hline 100os-iniz & $\Delta-\delta^{\circ} \cdot \Delta r$ & 7 & $x$ & 70 & $m$ \\
\hline ImL-ini: & $(8) \cdot(4)$ & $n$ & 2 & 3 & v \\
\hline 1ans-1en & $\$-\delta r+(\$)=10$ & 7 & 4 & 7 & $\pi$ \\
\hline 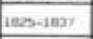 & $8.6 \cdot 8.8 n$ & 12 & 4 & 38 & $m$ \\
\hline Lexs, ans & $(\Delta \cdot \delta)-18 \cdot 8 \cdot 8$ & 2 & $s$ & 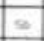 & $m$ \\
\hline Lexpesest & $\$ 3 \cdot 8=8,-8=0$ & 3 & $=$ & 4 & ext \\
\hline ine-ines & (0) $-188 \cdot 8.8$ & 2 & 6 & st & $\approx$ \\
\hline inesiess & $8 \cdot 8.8 \cdot 8.8 .8$ & 9 & 6 & 4 & $\mathrm{mr}$ \\
\hline Iessims & 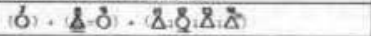 & 2 & 2 & 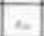 & $w$ \\
\hline amsinst & $31 \cdot 8-8 \cdot 8 \cdot 8 \cdot 8$ & 2 & 4 & 4 & $\mathrm{se}$ \\
\hline Iexc-10ses & $8+8.8 \cdot 8.81+8$ & 3 & 7 & this & $m$ \\
\hline 1enta-14000 & (8) $-8.01-8.87 .8 .8$ & 3 & s & an... & enn \\
\hline $1060-1662$ & $81 \cdot 8.8 \cdot 8 \cdot 8.81 \cdot 8.8$ & 2 & is & +6 & exper \\
\hline $180<-1000$ & $(61-8.81+8)+8.81-8.8 .8$ & 3 & 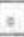 & is & ntrit \\
\hline -106s-1678 & $8.8+8+8.8 \cdot 8.8 .8$ & in & 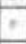 & $\approx$ & wक \\
\hline tems-14m & $(8-8), 8,8.8,-8.8 .8$ & $a$ & $s$ & $s$ & nem \\
\hline insolaseo & $8,8,8.8,-8: 8$ & 1 & 7 & 4 & $\mathrm{am}$ \\
\hline ime-1ment & $\Delta)=(\Delta .8) \cdot \Delta, 8,8$ & 2 & 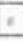 & 4 & 190 \\
\hline toen-times & $81,8.81 \cdot 8+8.8 r$ & $=$ & 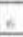 & 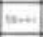 & inos. \\
\hline Ieus-imas & $(8)+18+8.8+8)+8.8+18$ & $z$ & e & 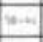 & mon \\
\hline ines-i904 & 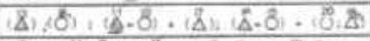 & s & 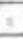 & $=0+4$ & $\operatorname{ses} m$ \\
\hline $1004-30 \times$ & $8+188, \cdot(8)+8-8) \cdot 8.8$ & 2 & 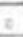 & in-s.5. & $\cos x$ \\
\hline $1506-2000$ & $81,181,8,8,18,8$ & 3 & 5 & 4 & ener \\
\hline 1907-1940 & $81,8.81 \cdot 18: 8$ & s, & 3 & 4 & $i=$ \\
\hline 190-1917: & $8.8 \cdot 18.8$ & $y$ & 4 & $x$ & $w$ \\
\hline 1017-4016 & 281.81 & 4 & 3 & 3 & $n$ \\
\hline tuin-1820 & $8.8 \cdot 8-8.8$ & 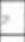 & 4 & * & wr \\
\hline $1826-1928$ & 8.8 & $=$ & $z$ & 3 & $=$ \\
\hline 71026-1907 & $8 .+18.8) \cdot 8.82$ & ? & 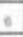 & $(\pi)$ & in \\
\hline $102 \%, \ldots$ & 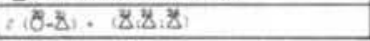 & & 2 & $\infty$ & is \\
\hline
\end{tabular}

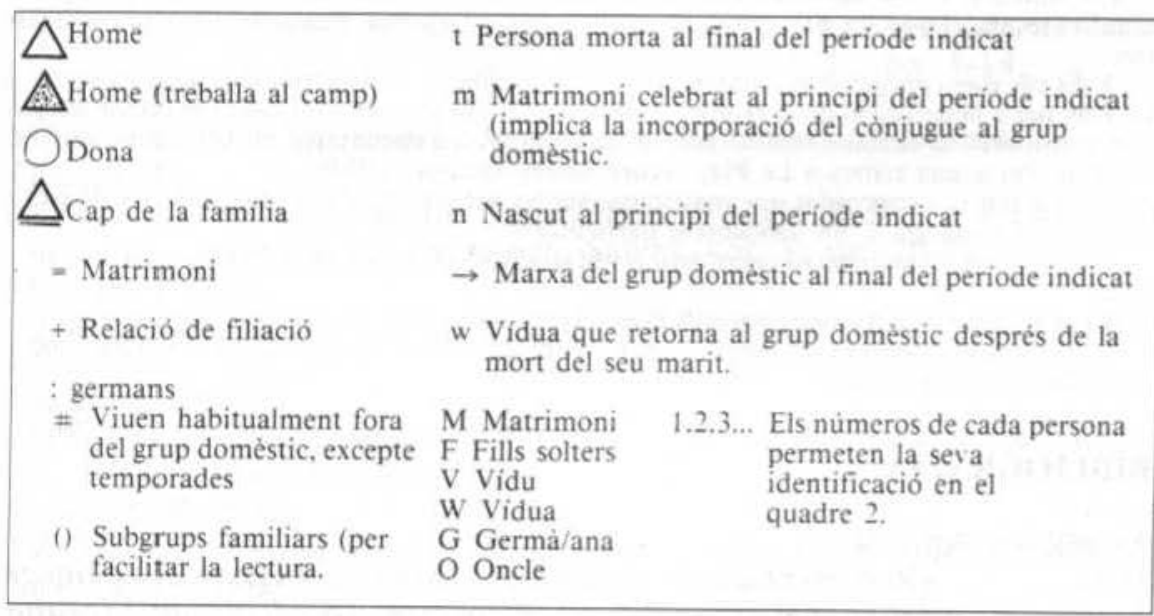

QUADRE 5. Evolució del cicle domèstic. Estructura del grup de residència. composició. tipologia i nombre de membres. 


\section{NOTES}

1. Aquest article s'inscriu dins d'un projecte de recerca que. a l'entorn de la familia. formes de residencia. propietat i herencia als segles XIX i XX. lautor desenvolupa a la comarca del Priorat. especialment als municipis de Gratallops i Torroja. Les dades daquest article foren recollides a partir del treball de camp desenvolupat a Gratallops i. en el cas d'aquest estudi de la familia Fabregat. a partir de documentació de la própia familia (Testaments i Capitols Matrimonials), del Jutjat i Ajuntament de Gratallops (Registre Civil: Registre de matrimonis. naixements i defuncions entre el 1870 i el 1930: Amillaraments i Cadastres de 1861.1930. 1945. 1963 i 1985: Censos de poblacio i padrons d habitants). de l'Arsiu Históric Arxidiocesà de Tarragona (Llibretes de Compliment Pasqual de Gratallops. entre 1792 i el 1890; Registre parroquial entre el 1826 i el 1860) i Arxiu Históric de Tarragona (Registre de la propietat urbana. 1920).

Dóno les gràcies a Dolors Comas d'Argemir, per la seva revisió d'aquest article. els seus suggeriments $\mathrm{i}$ interès que ha fet possible la seva publicació.

2. Dades procedents de: 1900 (Amillarament): 1963 (Cadastre).

3. Veure, en aquest sentit. els treballs de PERPINA (1932) i d'IGLESIES (1968).

4. Wolf ha definit com a "capitalisme de renda" un sistema com aquest. en quẻ els grans propietaris «intenten evitar els rises de producció al present i únicament procuren que els sistemes de recollir els pagaments siguin els més eficaçosm (Wolf. 1971:75).

5. Malgrat la generalització del Dret Civil català. els habitants de Catalunya Nova acostumen a destacar el fet que l'herència pugui dividir-se entre els diversos fills amb més facilitat. afirmació que comparteixen alguns estudis (veure Domingo. Ferrús. Rodriguez Solano. 1981: 3-18). Tanmateix. manca encara un treball que comprovi empiricament i estadisticament aquestes hipótesis. En la nostra perspectiva. aquest fet només pot entendre's tenint en compte les diferencies en l'estructura de classes. En un treball que estem realitzan al Priorat. ens proposem analitzar com. mentre les families benestants adoptarien normalment una herència indivisa (o fonamentalment indivisa). les families amb menvs propietats tendirien a la seva repartició.

6. Aquestes dades procedeixen de: 1792. Llibreta de Compliment Pasqual (Arxiu Arxidiocesá de Tarragona): 1975. Padró Municipal d'Habitants (Ajuntament de Gratallops), amb modificacions a partir de la comprovació en el treball de camp. Per a la seva classificació. adoptem la tipologia definida pel Grup de Cambridge (Laslett et al.. 1972:31). D'aquella classificació. només reproduïm les subcategories de les quals es dóna algun cas a Gratallops. D'altra banda. mantenim la distinció del tipus 6. com indica Flandrin (1979:316), malgrat que molts autors afegeixen aquestes combinacions als tipus 4 o 5 .

7. Fem aquesta constatació a partir del procès seguit per alguns casos particulars. En aquest moment estem realitzan una reconstrucció de l'evolució de l'heréncia de totes les families locals. el que ens permetrá una confirmació estadística d’aquesta primera constatació.

8. El cas més conegut d'una observació d'una familia és el dels Mélouga. que va servir a Le Play per a la definició de la familia troncal el qual. peró. no va introduir el factor temps. fins considerar la familia troncal com a una estructura immutable en un temps gairebé inmóbil. Per a una critica a Le Play, veure Assier-Andrieu. $1984 \mathrm{~b}$.

9. «Tractat (...) concordat que matrimoni sia fet per y entre Pau Fabregat (...) y de Rosa txonch», Gratallops. 1798. Document particular.

10. "Tractat de matrimoni entre Anton i Maria Ros». Gratallops. 1856. Document particular.

11. "Testament d'Antoni Fabregat Ros». Gratallops. 1878. Document particular.

12. "Contracte de conreu entre Llorenç Fabregat Ros i Miquel Caballé». Gratallops. 1917. Document particular.

\section{BIBLIOGRAFIA}

ASSIER-A.NDRIEU, L.

$1984 \quad$ «Representacions juridiques i conseqüències sociològiques del model domèstic als Pirineus". Quaderns de l'Institut Català d'Antropologia, 5: 9-27.

1984b «Le Play et la famille-souche des Pyrénées: politique, juri- 
BERKNER, L.K.

disme et science sociale», Annales E.S.C., n.3 (maig-juny): 495-512.

1975

"The Use and Misuse of Census Data for Historical Analysis of Family Structure», Journal of Interdisciplinary History, 4:

COLLOMP, A. $721-738$.

1974

«Ménage et famille. Etudes comparatives sur la dimension et la structure du groupe domestiquen, Annales E.S.C., 29: 777-786.

COMAS D'ARGEMIR, Dolors

1984 «La familia troncal en les transformacions del Pirineu d'ACUISINIER, Jean ragóm, Quaderns de l'Institut Català d'Antropologia, 5:44-68.

1976

"The domestic cycle in the traditional family organization in Tunisia", a PERISTIANY, J.G., (ed.): Mediterranean Family Structures. Cambridge. Cambridge University Press, pp. 137-155.

DOMINGO, M.; FERRUS, J.; RODRIGUEZ-SOLANO, M.Rosa

1981 «L'habitat dispers a la Catalunya Nova: un problema meto-

DONZELAT, J. dològic», Comentaris d'Antropologia .Cultural, 3: 3-18.

$1979 \quad$ La policia de las familias. Valencia. Pre-textos.

FLANDRIN, Jean Louis

1979 Origenes de la familia moderna. Barcelona. Crítica. Grijalbo.

FAUVE-CHAMOUX, A.

1984

«Les structures familiales au royaume des familles-souches:

FORTES, M.

Esparros», Annales E.S.C., n. 3 (maig-juny): 512-528.

1958

«Introduction», a GOODY, J. (ed.): The Development Cycle in Domestic Groups. Cambridge. C.U.P., pp. 1-14.

GALESKY, B.

1976 Sociologia del campesinado. Barcelona. Península.

GIRALT, E.

1978

"L'evolució de l'agricultura al segle XIX», a Història de

Catalunya. Barcelona. Salvat, vol. V, pp. 20-38.

Goody, J. (ed.)

1958 The Development Cycle in Domestic Groups. Cambridge. C.U.P.

IGLESIES, Josep

1968 La crisi agrària de 1798-1900. La fil.loxera a Catalunya.

Barcelona. Ed. 62.

LASLETT, P. et al.

1972 Household and family in past time. Cambridge. C.U.P. MOUNT, Ferdinand

1982 The subversive family. Londres. Unwin Paperbacks.

PERPIÑA GRAU, Romà

1932 La crisi del Priorat. Barcelona. Agricultura i Ramaderia. 
RoIGE, Xavier

$1984 \quad$ Agricultura, estructures culturals $i$ unitat de producció familiar al Priorat. Tesi de llicenciatura. Universitat de Barcelona (inèdit).

SiEder, R., MitTERAUER, M.

1983 «The reconstruction of the family life course: theoretical problems and empiricals results", a WALL, R.; ROBIN, J.; LASLETT, P.(eds.): Family Forms in Historic Europe. Cambridge. C.U.P. pp. 309-346.

STONE, Lawrence

1977 The family, sex and marriage in England 1500-1800. Londres. Weidenfeld and Nicolson.

TERRADES, Ignasi

1984 El món històric de les masies. Barcelona. Curial.

TENTORI, Tullio

1976 «Social classes and family in a Southern Italian town: Materas, a PERISTIANY, J.G. (ed.): Mediterranean Family Structu-

WOLF, E.R. res. Cambridge. C.U.P., pp. 273-285.

Los campesinos. Barcelona. Labor. 